\title{
$G A B R Q$ expression is a potential prognostic marker for patients with clear cell renal cell carcinoma
}

\author{
DONGJUN LEE ${ }^{1 *}$, MIHYANG HA $^{2 *}$, CHAE MI HONG $^{1}$, JAYOUNG KIM $^{1}$, SU MIN PARK ${ }^{1}$, \\ DONGSU PARK ${ }^{3-5}$, DONG HYUN SOHN ${ }^{6}$, HO JIN SHIN ${ }^{7}$, HAK-SUN YU ${ }^{8}$, CHI DAE KIM $^{9}$, \\ CHI-DUG KANG ${ }^{1,10}$, MYOUNG-EUN HAN ${ }^{2}$, SAE-OCK OH ${ }^{2}$ and YUN HAK KIM ${ }^{2,11,12}$
}

\begin{abstract}
Departments of ${ }^{1}$ Convergence Medical Science and ${ }^{2}$ Anatomy, Pusan National University School of Medicine, Yangsan, Gyeongsangnam-do 50612, Republic of Korea; Departments of ${ }^{3}$ Molecular Human Genetics, and ${ }^{4}$ Pathology and Immunology; ${ }^{5}$ Center for Skeletal Biology, Baylor College of Medicine, Houston, TX 77030, USA; Departments of ${ }^{6}$ Microbiology and Immunology, ${ }^{7}$ Hematology-Oncology, ${ }^{8}$ Parasitology, ${ }^{9}$ Pharmacology, ${ }^{10}$ Biochemistry, and

${ }^{11}$ Biomedical Informatics, Pusan National University School of Medicine, Yangsan, Gyeongsangnam-do 50612;

${ }^{12}$ Biomedical Research Institute, Pusan National University Hospital, Busan 49241, Republic of Korea
\end{abstract}

Received December 3, 2018; Accepted June 27, 2019

DOI: $10.3892 / \mathrm{ol} .2019 .10960$

\begin{abstract}
Clear cell renal cell carcinoma (ccRCC) is the most common type of kidney cancer. Novel biomarkers of ccRCC may provide crucial information on tumor features and prognosis. The present study aimed to determine whether the expression of $\gamma$-aminobutyric acid (GABA) A receptor subunit $\theta(G A B R Q)$ could serve as a novel prognostic marker of ccRCC. GABA is the main inhibitory neurotransmitter in the brain that activates the receptor $\mathrm{GABA}_{\mathrm{A}}$, which is comprised of three subunit isoforms: GABRA3, GABRB3 and GABRQ. A recent study reported that GABRQ is involved in the initiation and progression of hepatocellular carcinoma; however, the role of GABRQ in ccRCC remains unknown. In the present study, clinical and transcriptomic data were obtained from cohorts of the International Cancer Genome Consortium (ICGC) and The Cancer Genome Atlas (TCGA). Differential GABRQ expression levels among early (TI and II), late (TIII and IV), nonmetastatic (M0) and metastatic (M1, primary tumor) stages of ccRCC samples were then identified. Furthermore, the use of $G A B R Q$ as a prognostic gene was analyzed using Uno's $\mathrm{C}$-index based on the time-dependent area under the curve
\end{abstract}

Correspondence to: Professor Sae-Ock Oh and Professor Yun Hak Kim, Department of Anatomy, Pusan National University School of Medicine, 49 Busandaehak-ro, Yangsan, Gyeongsangnam-do 50612, Republic of Korea

E-mail: hedgehog@pusan.ac.kr

E-mail: yunhak10510@pusan.ac.kr

*Contributed equally

Key words: $\gamma$-aminobutyric acid receptor A subunit $\theta$, clear cell renal cell carcinoma, prognosis, The Cancer Genome Atlas, International Cancer Genome Consortium
(AUC), the AUC of the receiver operating characteristic curve at 5 years, the Kaplan-Meier survival curve and multivariate analysis. The survival curve analysis revealed that low $G A B R Q$ mRNA expression was significantly associated with a poor prognosis of ccRCC $(\mathrm{P}<0.001$ and $\mathrm{P}=0.0012$ for TCGA and ICGC data, respectively). In addition, analyses of the $\mathrm{C}$-index and AUC values further supported this discriminatory power. Furthermore, the prognostic value of $G A B R Q$ mRNA expression was confirmed by multivariate Cox regression analysis. Taken together, these results suggested that $G A B R Q$ mRNA expression may be considered as a novel prognostic biomarker of ccRCC.

\section{Introduction}

Kidney cancer is one of the top 10 types of cancer in terms of incidence and mortality rate in men and women, worldwide. Renal cell carcinoma (RCC) accounts for $~ 90 \%$ of all kidney cancer cases $(1,2)$. RCC mainly includes the papillary subtype, the chromophobe subtype and clear cell RCC (ccRCC) (3); ccRCC is the most common subtype. Furthermore, $30 \%$ of patients with kidney cancer present with metastatic disease (4). Surgical resection remains the most effective therapeutic strategy against clinically localized ccRCC. In addition, current treatments are focused on vascular endothelial growth factor receptor (VEGFR)-targeted therapy and mammalian target of rapamycin (mTOR) inhibition $(5,6)$. However, $30 \%$ patients with ccRCC are already at an advanced stage at the time of diagnosis (7), and the current therapeutic strategies offer limited efficacy. The development of novel therapeutic drugs for ccRCC is therefore challenging and it is crucial to determine efficient prognostic biomarkers of ccRCC in order to develop an effective treatment.

As the best-known inhibitory neurotransmitter in the brain, $\gamma$-aminobutyric acid (GABA) activates three pharmacologically and structurally distinct classes of receptor: $\mathrm{GABA}_{\mathrm{A}}$, $\mathrm{GABA}_{\mathrm{B}}$ and $\mathrm{GABA}_{\mathrm{C}}(8)$. Among them, GABA $\mathrm{A}$ is the major 
inhibitory receptor in the central nervous system $(9,10)$. Notably, $\mathrm{GABA}_{\mathrm{A}}$ receptor subunit $\theta(\mathrm{GABRQ})$ can bind with other receptors to form a functional chloride channel that mediates inhibitory synaptic transmission in the mature central nervous system (9). GABA and receptor $\mathrm{GABA}_{\mathrm{A}}$ are also present in peripheral tissues, including cancerous cells, but their precise function is poorly understood (10). A previous study revealed that GABRQ is overexpressed in hepatocellular carcinoma and that GABA promotes the proliferation of cancer cells through GABRQ (11). However, the prognostic significance of GABRQ in ccRCC remains unknown. To the best of our knowledge, the present study was the first to report on the mRNA expression levels of $G A B R Q$ in samples obtained from the International Cancer Genome Consortium (ICGC) (12) and The Cancer Genome Atlas (TCGA) $(13,14)$ primary-ccRCC cohorts. The results suggested that the mRNA expression levels of $G A B R Q$ may be considered an effective prognostic marker of ccRCC.

\section{Materials and methods}

Patient data and characteristics. The clinical and transcriptomic data from patients with ccRCC were downloaded from TCGA $(13,14)$ and ICGC (12) databases in March 2018. To identify the prognostic significance of $G A B R Q$ (Table I). TCGA and ICGC databases are approved for the quality of patient data and are widely used in numerous studies. No additional quality assessment was performed, since data that were not produced by a reputable institution were excluded. Samples with insufficient survival information were excluded $(15,16)$. The overall study workflow is presented in Fig. 1. Comparative analyses between normal and tumor cells was conducted with the use of publicly available microarray data from the Oncomine database. To relate $G A B R Q$ copy number (17), the GSE20306 dataset $(n=449)$ was used.

Statistical analyses. Wilcoxon's rank-sum test was performed to identify the differences in $G A B R Q$ expression between early and late stages of ccRCC in TCGA and ICGC cohorts. Survival analyses to predict overall survival of patients with ccRCC and the associated statistical analyses were conducted using R software (version 3.5.0; The R Foundation for Statistical Computing; 2018; http://www.R-project.org). Furthermore, to validate the prognostic value of $G A B R Q$, the following statistical methods were carried out: i) Uno's C-index; ii) area under the curve (AUC) in receiver operating characteristics (ROC) at 5 years; and iii) P-value from log-rank test of Kaplan-Meier survival curve to evaluate the accuracy of the discrimination, as described previously using the 'survival' and 'survAUC' $\mathrm{R}$ packages $(16,18)$. The $\mathrm{C}$-index is a well-known parameter of the fit of a survival model within a continuous time period during a clinical study $(19,20)$. Regarding the survival curve analyses, the optimal cutoff value that had the maximal Uno's $\mathrm{C}$-index by 5 -fold cross-validation was determined as previously described $(15,16,18)$. Since the RNA sequencing data from TCGA and ICGC had been obtained using different sequencing and normalization methods, the absolute value of gene expression varied widely among datasets. For these reasons, the optimal cutoff values were different for each cohort. $\mathrm{T}$ and $\mathrm{M}$ stage information in both cohorts was sufficient to perform subgroup analysis; however, as there
Table I. Characteristics of patients from TCGA and ICGC databases.

\begin{tabular}{lcc}
\hline Characteristic & TCGA $(\%)$ & ICGC (\%) \\
\hline ATCC stage & & \\
I & $216(48.4)$ & $48(52.7)$ \\
II & $46(10.3)$ & $12(13.2)$ \\
III & $111(24.9)$ & $13(14.3)$ \\
IV & $71(15.9)$ & $9(9.9)$ \\
Not available & $2(0.4)$ & $9(9.9)$ \\
Grade & & \\
I & $9(2.0)$ & - \\
II & $189(42.4)$ & - \\
III & $175(39.2)$ & - \\
IV & $68(15.2)$ & - \\
Not available & $5(1.1)$ & - \\
Sex & & \\
Male & $290(65.0)$ & $52(57.1)$ \\
Female & $156(35.0)$ & $39(42.9)$ \\
Age (mean \pm standard & $60.62 \pm 12.80$ & $60.47 \pm 10.03$ \\
deviation) & & 91 \\
Total number of patients & 446 & 91 \\
\hline
\end{tabular}

AJCC, American Joint Committee on Cancer; ICGA, International Cancer Genome Consortium; TCGA, The Cancer Genome Atlas.

Table II. Optimal cutoff values for $\gamma$-aminobutyric acid receptor A subunit $\theta$ expression in TCGA and ICGC cohorts.

\begin{tabular}{lc}
\hline Dataset & Cutoff value \\
\hline TCGA & 4.9689 \\
ICGC & 0.1440 \\
\hline
\end{tabular}

ICGA, International Cancer Genome Consortium; TCGA, The Cancer Genome Atlas.

was no information for $\mathrm{N}$ stage, subgroup analysis was not performed (12-14). Univariate and multivariate Cox regression analyses were performed to compare the effects of $G A B R Q$ expression (as a categorical value) on prognosis and other clinical variables.

\section{Results}

Patient characteristics. A total of 446 and 91 patients from the TCGA and ICGC databases, respectively, were analyzed in the present study $(12-14,21,22)$. The 446 patients from TCGA comprised 290 men and 156 women. The 91 patients from the ICGC comprised 52 men and 39 women. The patient characteristics investigated in the present study are listed in Table I.

Downregulation of GABRQ at late stages of $c c R C C$. The mRNA expression levels of $G A B R Q$ were compared among 


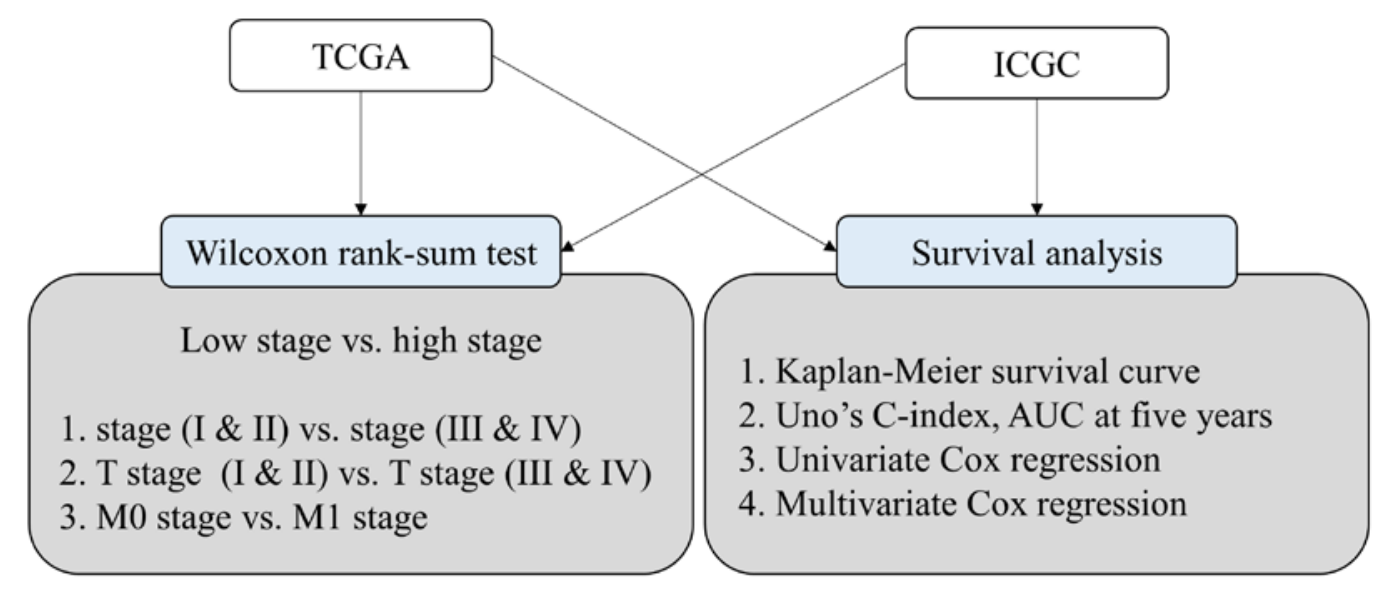

Figure 1. Flowchart of the present study. AUC, area under the curve; ICGA, International Cancer Genome Consortium; TCGA, The Cancer Genome Atlas.
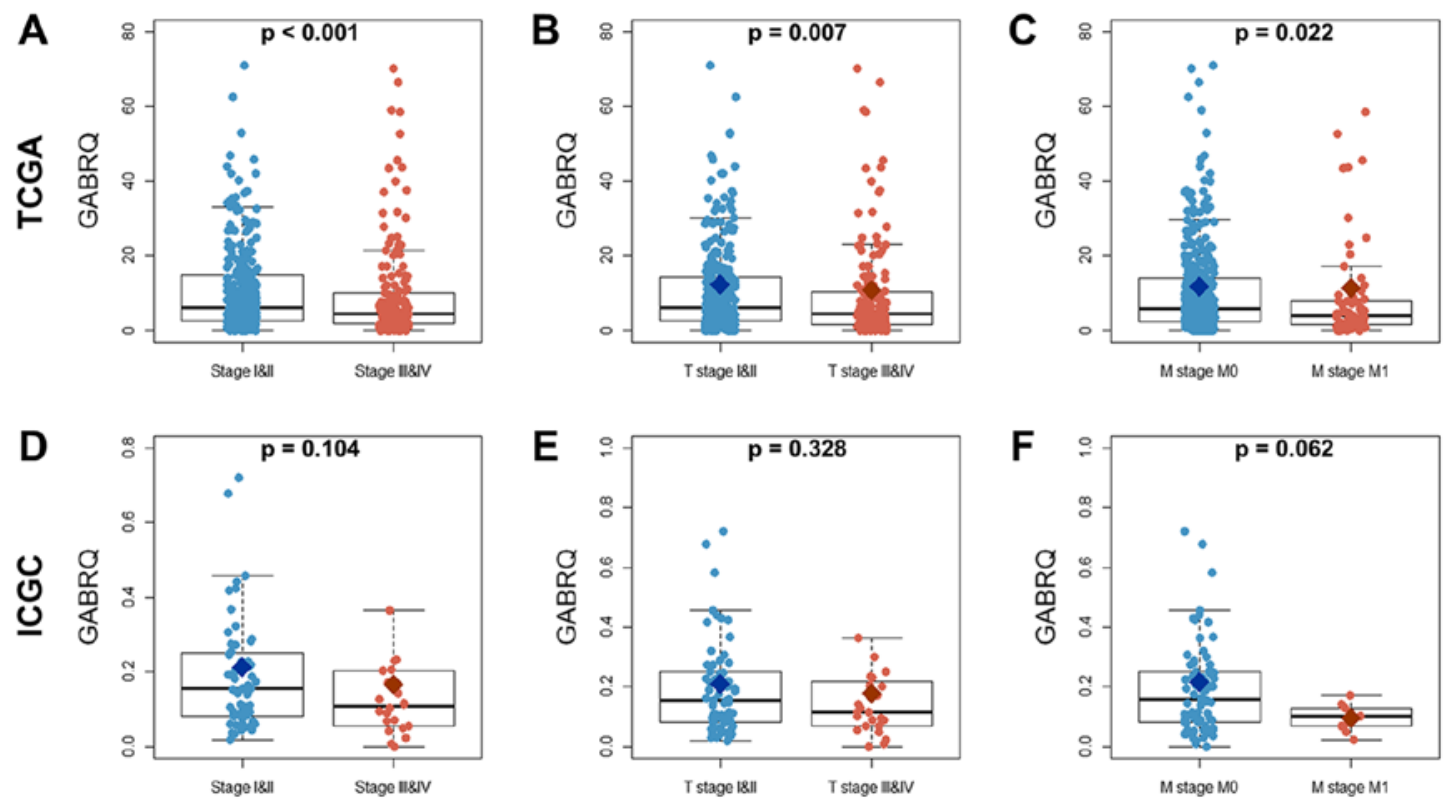

Figure 2. Comparison of GABRQ mRNA expression among early (TI and II), late (TIII and IV), nonmetastatic (M0), and metastatic (M1, primary tumor) stages of ccRCC samples from TCGA and ICGC cohorts. (A-C) GABRQ expression values in ccRCC samples from TCGA cohort. (D-F) GABRQ expression values in ccRCC samples from ICGC cohort. ccRCC, clear cell renal cell carcinoma; $G A B R Q, \gamma$-aminobutyric acid receptor A subunit $\theta$; ICGA, International Cancer Genome Consortium; TCGA, The Cancer Genome Atlas.

samples from early (TI and II), late (TIII and IV), nonmetastatic (M0) and metastatic (M1, primary tumor) stages of ccRCC (Table II) from TCGA and ICGC cohorts. The mRNA expression levels of $G A B R Q$ were much higher in early (TI and II) and nonmetastatic (M0) ccRCC samples compared with in late (TIII and IV) and metastatic (M1, primary tumor) ccRCC samples in TCGA (Fig. 2). The similar trend was seen in the ICGC but this was not statistically significant. In addition, $G A B R Q$ copy numbers are decreased in several types of cancers, including kidney cancers, leukemia, multiple myeloma and prostate cancers (Fig. 3).

Prognostic value of GABRQ mRNA expression in patients with $c c R C C$. To identify the prognostic significance of $G A B R Q$ in ccRCC, survival curves for $G A B R Q$ mRNA expression
(Table II) and survival within TCGA (Fig. 4) and ICGC (Fig. 5) cohorts were analyzed. Patients with low $G A B R Q$ mRNA expression in the primary tumor in the two cohorts had significantly shorter overall survival time compared with patients with higher GABRQ mRNA expression (Figs. 4 and 5). Prognostic value was then examined using multivariate Cox regression analysis (Table III). The multivariate analysis conformed that GABRQ mRNA expression was an independent prognostic factor for ccRCC.

$C$-index and $A U C$ of GABRQ. To assess whether GABRQ mRNA expression could be considered a prognostic biomarker of ccRCC, Uno's C-index based on the time-dependent AUC analysis and the AUC of the receiver operating characteristic curve at 5 years were examined. The results demonstrated that $G A B R Q$ mRNA had high C-index values in the two 


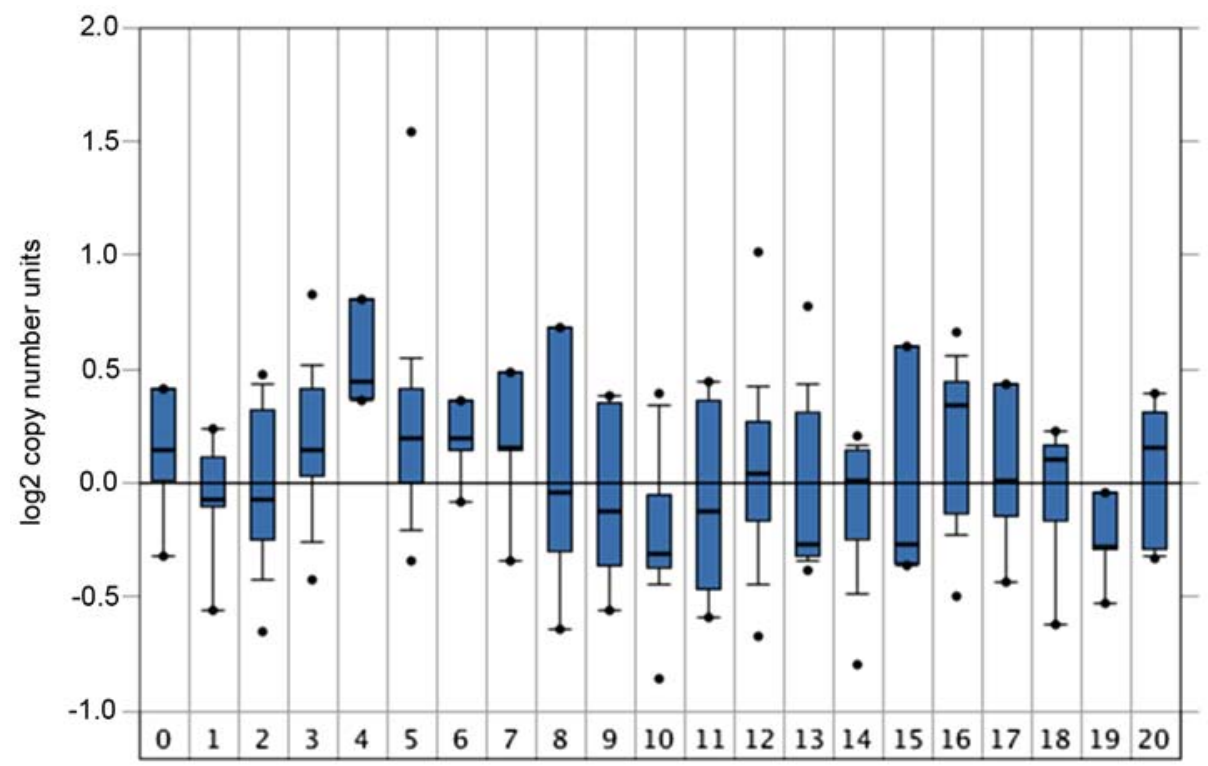

Figure 3. GABRQ gene expression in tumors. The copy number of GABRQ in tumors in the Oncomine database corresponds to the GSE20306 dataset $(\mathrm{n}=449)$ (36). The $\mathrm{x}$-axis represents the number of patients with different types of cancer: 0, Normal ( $\mathrm{n}=4)$; 1, Bladder ( $\mathrm{n}=9$ ); 2, Brain and central nervous system ( $\mathrm{n}=17) ; 3$, Breast $(\mathrm{n}=21)$; 4, Cervical $(\mathrm{n}=7) ; 5$, Colorectal $(\mathrm{n}=21) ; 6$, Esophageal $(\mathrm{n}=4) ; 7$, Gastric $(\mathrm{n}=5) ; 8$, Head and neck $(\mathrm{n}=6) ; 9$, Kidney $(\mathrm{n}=8) ; 10$, Leukemia ( $\mathrm{n}=33)$; 11, Liver ( $\mathrm{n}=9) ; 12$, Lung ( $\mathrm{n}=78)$; 13, Lymphoma ( $\mathrm{n}=41) ; 14$, Melanoma $(\mathrm{n}=12) ; 15$, Myeloma $(\mathrm{n}=5)$; 16, Other $(\mathrm{n}=7)$; 18, Pancreatic $(\mathrm{n}=9)$; 19, Prostate $(\mathrm{n}=5)$ and 20, Sarcoma $(\mathrm{n}=20)$. GABRQ, $\gamma$-aminobutyric acid receptor A subunit $\theta$.
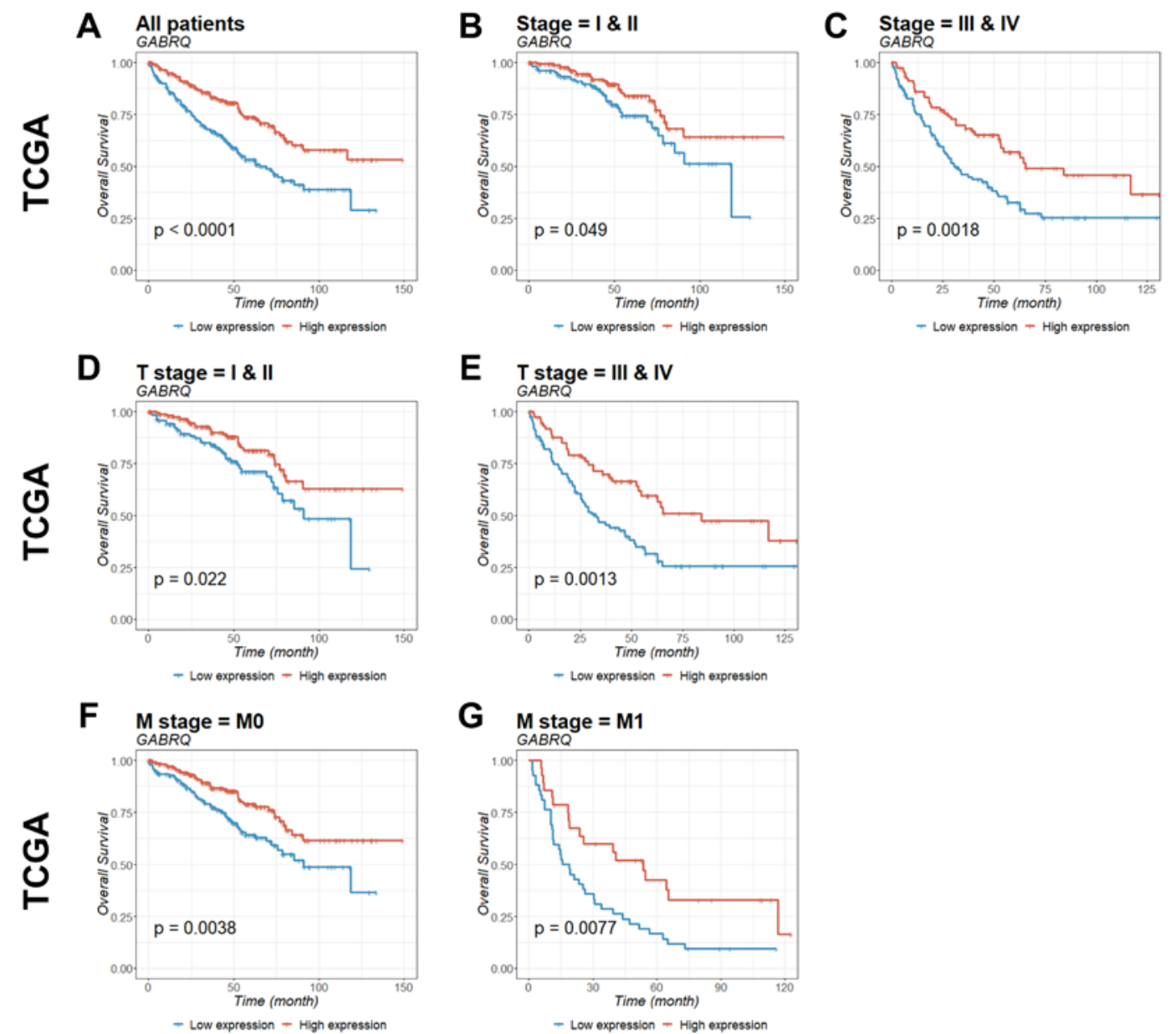

Figure 4. Kaplan-Meier estimation of $G A B R Q$ mRNA expression as a prognostic biomarker in patients with ccRCC. The association of GABRQ gene expression with overall survival among patients from TCGA was examined. Gene expression was analyzed for (A) all patients, (B) stage I and II, (C) stage III and IV, (D) T stage I and II, (E) T stage III and IV, (F) M stage 0, and (G) M stage 1. P-values were calculated by the log-rank test and are provided in the bottom left of each plot. ccRCC, clear cell renal cell carcinoma; GABRQ, $\gamma$-aminobutyric acid receptor A subunit $\theta$; TCGA, The Cancer Genome Atlas; M0, non-metastatic; M1, primary tumor. 
Table III. Univariate and multivariate analyses of overall survival in each cohort.

\section{A, TCGA}

\begin{tabular}{|c|c|c|c|c|c|c|c|c|}
\hline \multirow{3}{*}{$\begin{array}{l}\text { Variable } \\
G A B R Q \text { (categorical) }\end{array}$} & \multicolumn{4}{|c|}{ Univariate Cox regression } & \multicolumn{4}{|c|}{ Multivariate Cox regression } \\
\hline & \multirow{2}{*}{$\begin{array}{l}\text { P-value } \\
<0.001^{\mathrm{c}}\end{array}$} & \multirow{2}{*}{$\begin{array}{c}\text { Hazard ratio } \\
0.483\end{array}$} & \multicolumn{2}{|c|}{$95 \%$ confidence interval } & \multirow{2}{*}{$\begin{array}{l}\text { P-value } \\
<0.001^{c}\end{array}$} & \multirow{2}{*}{$\begin{array}{c}\text { Hazard ratio } \\
0.562\end{array}$} & \multicolumn{2}{|c|}{$95 \%$ confidence interva } \\
\hline & & & 0.348 & 0.672 & & & 0.401 & 0.788 \\
\hline Age & $<0.001^{\mathrm{c}}$ & 1.033 & 1.018 & 1.047 & $<0.001^{\mathrm{c}}$ & 1.030 & 1.015 & 1.046 \\
\hline Stage (I, II vs. III, IV) & $<0.001^{\mathrm{c}}$ & 3.478 & 2.474 & 4.888 & $<0.001^{\mathrm{c}}$ & 2.883 & 2.012 & 4.132 \\
\hline $\begin{array}{l}\text { Sex } \\
\text { (female vs. male) }\end{array}$ & 0.333 & 0.850 & 0.612 & 1.181 & 0.859 & 0.969 & 0.688 & 1.366 \\
\hline $\begin{array}{l}\text { Grade } \\
(\mathrm{I}, \mathrm{II} \text { vs. III, IV) }\end{array}$ & $<0.001^{\mathrm{c}}$ & 2.247 & 1.572 & 3.212 & 0.135 & 1.340 & 0.913 & 1.968 \\
\hline
\end{tabular}

B, ICGC

Variable
Univariate Cox regression

Univariate Cox regression

P-value Hazard ratio $95 \%$ confidence interval
Multivariate Cox regression

P-value Hazard ratio $95 \%$ confidence interval

\begin{tabular}{|c|c|c|c|c|c|c|c|c|}
\hline$G A B R Q$ (categorical) & $0.002^{\mathrm{b}}$ & 0.283 & 0.126 & 0.638 & $0.014^{\mathrm{a}}$ & 0.343 & 0.146 & 0.804 \\
\hline Age & 0.109 & 1.031 & 0.993 & 1.071 & 0.448 & 1.015 & 0.976 & 1.056 \\
\hline $\begin{array}{l}\text { Stage } \\
\text { (I, II vs. III, IV) }\end{array}$ & $<0.001^{\mathrm{c}}$ & 4.796 & 2.264 & 10.16 & $<0.001^{\mathrm{c}}$ & 4.628 & 2.094 & 10.232 \\
\hline $\begin{array}{l}\text { Sex } \\
\text { (female vs. male) }\end{array}$ & 0.863 & 1.066 & 0.517 & 2.194 & 0.307 & 0.657 & 0.294 & 1.470 \\
\hline
\end{tabular}

${ }^{\mathrm{a}} \mathrm{P}<0.05,{ }^{\mathrm{b}} \mathrm{P}<0.01$ and ${ }^{\mathrm{c}} \mathrm{P}<0.001 . G A B R Q, \gamma$-aminobutyric acid receptor A subunit $\theta$; ICGA, International Cancer Genome Consortium; TCGA, The Cancer Genome Atlas.

Table IV. C-index values of $G A B R Q$ in the specified categories of TCGA and ICGC cohorts.

\begin{tabular}{lcc}
\hline & \multicolumn{2}{c}{ C-index } \\
\cline { 2 - 3 } Categories & TCGA & ICGC \\
\hline All patients & 0.644 & 0.670 \\
Stage I \& II & 0.597 & 0.639 \\
Stage III \& IV & 0.634 & 0.585 \\
T (I \& II) & 0.600 & 0.621 \\
T (III \& IV) & 0.645 & 0.671 \\
M0 & 0.623 & 0.652 \\
M1 & 0.644 & 0.655 \\
\end{tabular}

ICGA, International Cancer Genome Consortium; TCGA, The Cancer Genome Atlas.

independent cohorts (TCGA: 0.644 and ICGC: 0.670; Fig. 6A and Table IV). The 5-year ROC curves yielded high AUC values for both TCGA and ICGC (0.611 and 0.650, respectively; Fig. 6B). These results suggest that GABRQ mRNA expression is useful to predict prognosis of patients with ccRCC.

\section{Discussion}

Classification of ccRCC includes localized and advanced ccRCC. Numerous therapeutic options are currently available for localized ccRCC; however the most effective therapy remains surgical resection. Furthermore, there are no suitable drugs for the adjuvant treatment of local kidney cancer (23). Current treatments of advanced ccRCC target VEGFR and mTOR (24). Due to recent advances in biotechnology, including next-generation sequencing, bioinformatics has rapidly developed and highlighted a great number of potential biomarkers (25). Numerous patient databases are freely available to the public, including the Gene Expression Omnibus and TCGA, which contain extensive gene expression data that can be used to determine novel biomarkers (26). Notably, these databases can be used to identify essential biomarkers for effective prognosis of ccRCC. In addition, molecular markers that can be used in combination with the current cancer staging systems need to be identified.

The present study demonstrated that $G A B R Q$ mRNA expression could be a prognostic marker of ccRCC. In particular, low $G A B R Q$ mRNA expression was associated with a poor prognosis among patients with ccRCC. A previous study indicated that $G A B R Q$ is overexpressed in hepatocellular carcinoma and that GABA promotes the proliferation 

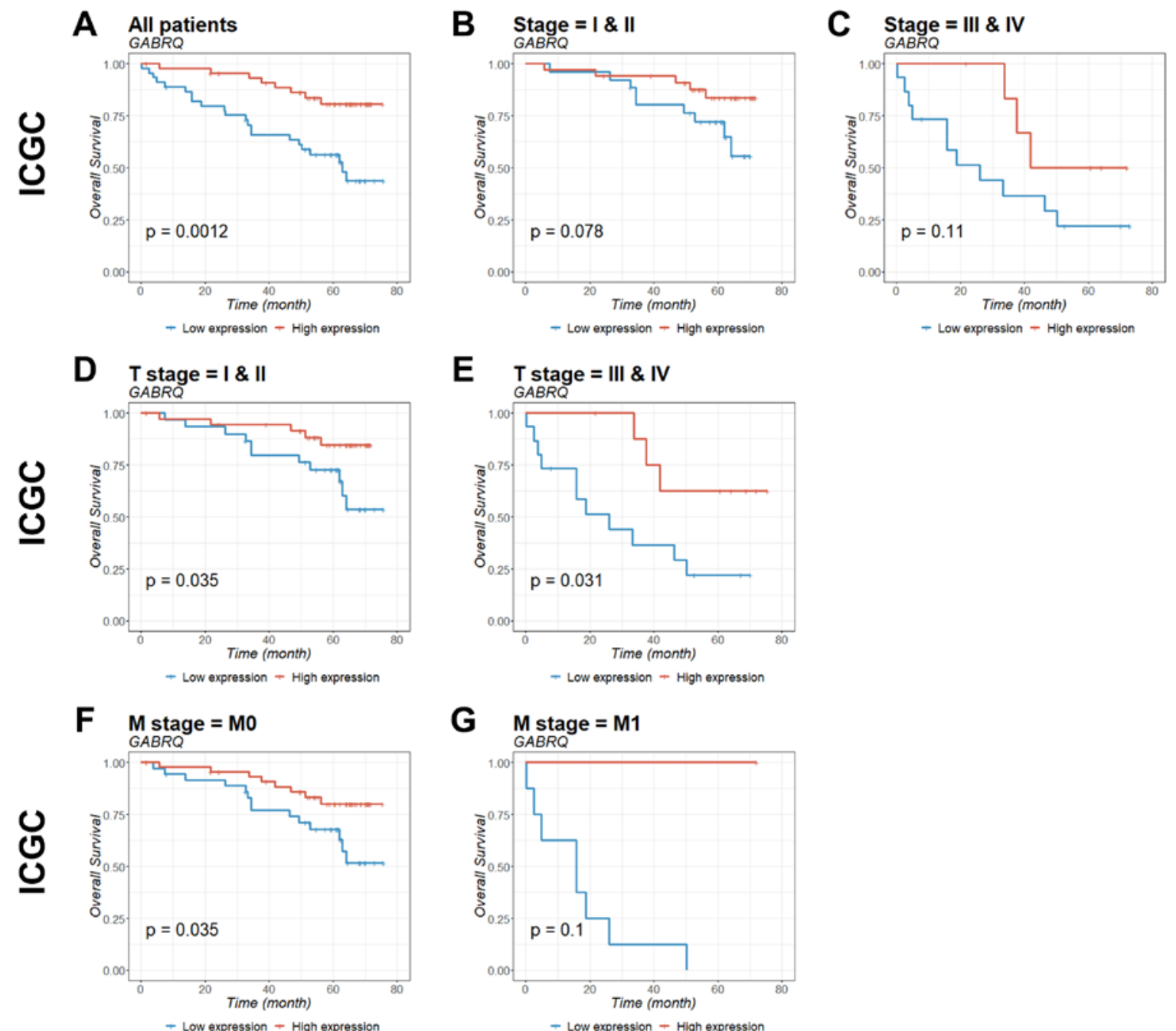

Figure 5. Kaplan-Meier estimation of $G A B R Q$ mRNA expression as a prognostic biomarker in patients with ccRCC. The association of $G A B R Q$ gene expression with overall survival among patients from the ICGC was examined. Gene expression was analyzed for (A) all patients, (B) stage I and II, (C) stage III and IV, (D) T stage I and II, (E) T stage III and IV, (F) M stage 0 , and (G) M stage 1. P-values were calculated by the log-rank test and are provided in the bottom left of each plot. ccRCC, clear cell renal cell carcinoma; GABRQ, $\gamma$-aminobutyric acid receptor A subunit $\theta$; ICGC, International Cancer Genome Consortium; M0, non-metastatic; M1, primary tumor.
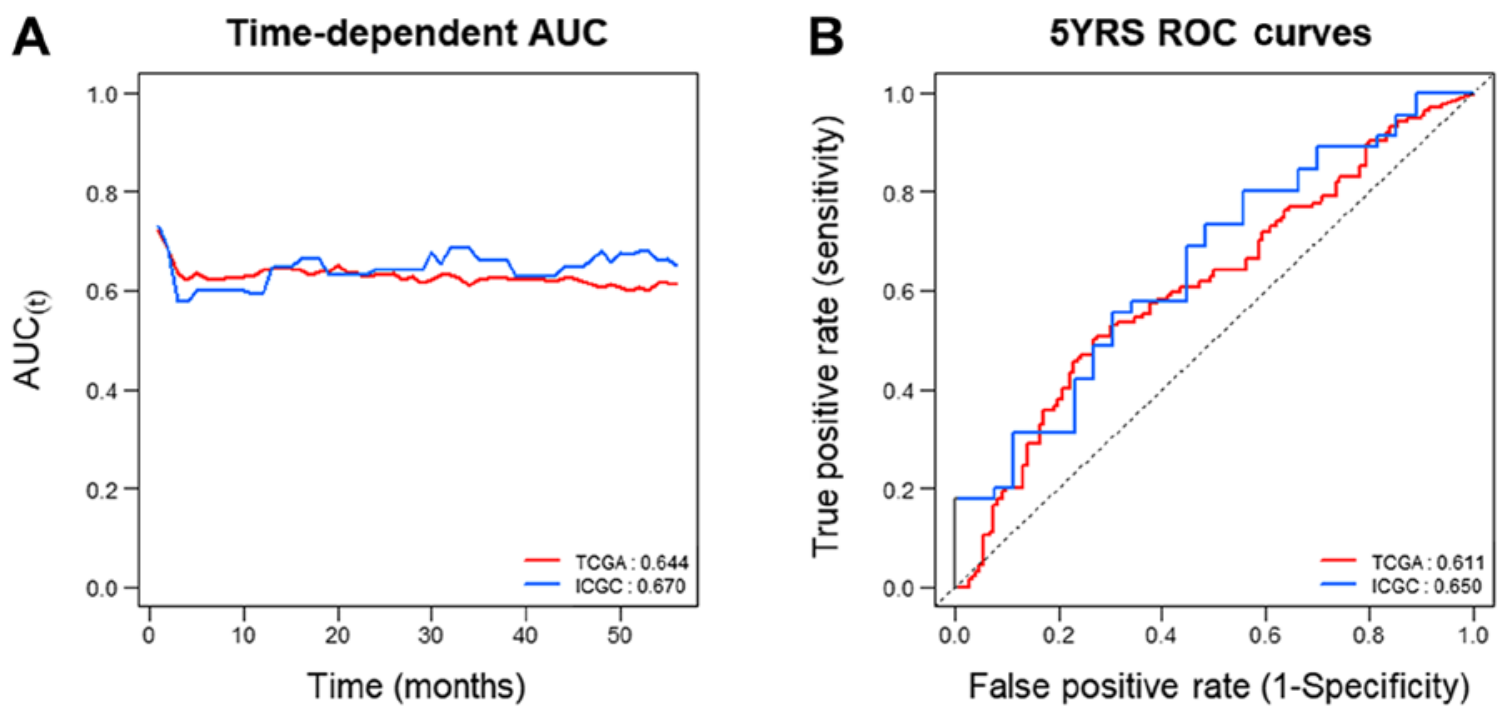

Figure 6. Time-dependent AUC and ROC curve analysis at 5 years according to GABRQ mRNA expression in TCGA and ICGC samples. Analysis of $G A B R Q$ gene expression in TCGA (red) and ICGC (blue) samples according to (A) time-dependent AUC and (B) ROC curve at 5 years. C-index values are provided in the bottom right corner of each plot. AUC, area under the curve; GABRQ, $\gamma$-aminobutyric acid receptor A subunit $\theta$; ICGA, International Cancer Genome Consortium; ROC, receiver operating characteristic; TCGA, The Cancer Genome Atlas. 
of cancer cells through GABRQ (11). In addition, GABA can inhibit colon cancer cell migration associated with the norepinephrine-induced pathway (27), and via the $\mathrm{GABA}_{\mathrm{B}}$ pathway, which is involved in prostate cancer metastasis and invasion (28). Although GABRQ may contribute to cancer progression, it has been reported that it can serve additional roles in other types of disease, including essential tremor (8) and migraines (29).

This study presented some methodological limitations. Since the expression data of $G A B R Q$ in the two independent cohorts were obtained through different methods, the absolute expression values differed for each cohort. The cutoff values of $G A B R Q$ were therefore different for each cohort. Most cohort studies present the same technical limitations, unless data processing was performed by the same hospital and at the same time. To identify the involvement of GABRQ in ccRCC, experiments need to be conducted at the protein level. However, there are numerous studies that have determined prognostic biomarkers based on mRNA expression (for example oncotype DX (30), MammaPrint (31) and gene signatures tests (19,32-34)). Although the present study did not confirm GABRQ function at the protein level, mRNA-based studies are emerging in this field, and represent time- and cost-effective methods.

The main conclusions from the present study may strengthen the foundation of precision medicine via analysis of transcriptomic data. mRNA-based prognostic markers have been identified in numerous diseases, including cancer, and certain markers are so accurate that they can be included in clinical guidelines (19,32,35-37). The results from both cohorts analyzed in this study demonstrated that lower GABRQ mRNA expression was associated with a worse ccRCC prognosis. In addition, $G A B R Q$ copy numbers were much lower in numerous types of cancer, including kidney cancer, leukemia, multiple myeloma and prostate cancer, according to genomic analyses from Oncomine (17) (Fig. 6). Although there are limitations to transcriptome-based studies of $G A B R Q$, the results from the present study suggested that $G A B R Q$ mRNA expression may be considered a novel prognostic biomarker of ccRCC.

\section{Acknowledgements}

Not applicable.

\section{Funding}

The present study was supported by the MRC program (grant no. NRF-2015R1A5A2009656), the National Research Foundation of Korea (NRF) funded by the Korean government (MSIT) (grant no. NRF-2018R1C1B6001290) and the Convergence Medical Institute of Technology R\&D project (grant no. CMIT2019-03) of Pusan National University Hospital. In addition, this work was supported by the Collaborative Genome Program for Fostering New Post-Genome Industry of the NRF funded by the Korean government (MSIT; grant no. NRF-2017M3C9A6047610).

\section{Availability of data and materials}

The datasets used and/or analyzed during the current study are available from the corresponding author on reasonable request.

\section{Authors' contributions}

$\mathrm{DL}, \mathrm{MH}, \mathrm{SOO}$ and YHK contributed to the design of the study. CMH, JYK, SMP, DSP, DHS, HJS, HSY, CDKi, CDKa and MEH acquired the data. MH, YH, DSP, DHS, HJS, HSY, CDKi, CDKa and MEH acquired and analyzed the data. DL, SOO and YHK drafted the manuscript. DL, DSP, DHS, HJS, HSY, CDKi, CDKa, MEH, SOO and YHK revised and edited the manuscript. DL, SOOO and YHL acquired funding, resources and supervised the project.

\section{Ethics and consent to participate}

Not applicable.

\section{Patient consent for publication}

Not applicable.

\section{Competing interests}

The authors declare that they have no competing interests.

\section{References}

1. Siegel RL, Miller KD and Jemal A: Cancer statistics, 2018. CA Cancer J Clin 68: 7-30, 2018.

2. Choueiri TK and Motzer RJ: Systemic therapy for metastatic renal-cell carcinoma. N Engl J Med 376: 354-366, 2017.

3. Srigley JR, Delahunt B, Eble JN, Egevad L, Epstein JI, Grignon D, Hes O, Moch H, Montironi R, Tickoo SK, et al: The international society of urological pathology (ISUP) Vancouver classification of renal Neoplasia. Am J Surg Pathol 37: 1469-1489, 2013.

4. Nickerson ML, Jaeger E, Shi Y, Durocher JA, Mahurkar S, Zaridze D, Matveev V, Janout V, Kollarova H, Bencko V, et al: Improved identification of von Hippel-Lindau gene alterations in clear cell renal tumors. Clin Cancer Res 14: 4726-4734, 2008.

5. Powles T, Albiges L, Staehler M, Bensalah K, Dabestani S, Giles RH, Hofmann F, Hora M, Kuczyk MA, Lam TB, et al: Updated European association of urology guidelines recommendations for the treatment of first-line metastatic clear cell renal cancer. Eur Urol: Dec 7, 2017 doi: 10.1016/j.eururo.2017.11.016 (Epub ahead of print).

6. Powles T, Staehler M, Ljungberg B, Bensalah K, Canfield SE, Dabestani S, Giles R, Hofmann F, Hora M, Kuczyk MA, et al: Updated EAU Guidelines for clear cell renal cancer patients who fail vegf targeted therapy. Eur Urol 69: 4-6, 2016.

7. Karakiewicz PI, Briganti A, Chun FK, Trinh QD, Perrotte P, Ficarra V, Cindolo L, De la Taille A, Tostain J, Mulders PF, et al: Multi-institutional validation of a new renal cancer-specific survival nomogram. J Clin Oncol 25: 1316-1322, 2007.

8. Garcia-Martin E, Martinez C, Alonso-Navarro $\mathrm{H}$, Benito-León J, Lorenzo-Betancor O, Pastor P, Puertas I, Rubio L, López-Alburquerque T, Agúndez JA and Jiménez-Jiménez FJ: Gamma-aminobutyric acid GABRA4, GABRE, and GABRQ receptor polymorphisms and risk for essential tremor. Pharmacogenet Genomics 21: 436-439, 2011.

9. Neelands TR, Zhang J and Macdonald RL: GABA(A) receptors expressed in undifferentiated human teratocarcinoma NT2 cells differ from those expressed by differentiated NT2-N cells. J Neurosci 19: 7057-7065, 1999.

10. Haydar TF, Wang F, Schwartz ML and Rakic P: Differential modulation of proliferation in the neocortical ventricular and subventricular zones. J Neurosci 20: 5764-5774, 2000.

11. Li YH, Liu Y, Li YD, Liu YH, Li F, Ju Q, Xie PL and Li GC: GABA stimulates human hepatocellular carcinoma growth through overexpressed GABAA receptor theta subunit. World J Gastroenterol 18: 2704-2711, 2012.

12. International Cancer Genome Consortium; Hudson TJ, Anderson W, Artez A, Barker AD, Bell C, Bernabé RR, Bhan MK, Calvo F, Eerola I, et al: International network of cancer genome projects. Nature 464: 993-998, 2010. 
13. Cerami E, Gao J, Dogrusoz U, Gross BE, Sumer SO, Aksoy BA Jacobsen A, Byrne CJ, Heuer ML, Larsson E, et al: The cBio cancer genomics portal: An open platform for exploring multidimensional cancer genomics data. Cancer Discov 2: 401-404, 2012.

14. Cancer Genome Atlas Research Network; Weinstein JN Collisson EA, Mills GB, Shaw KR, Ozenberger BA, Ellrott K, Shmulevich I, Sander C and Stuart JM: The cancer genome atlas pan-cancer analysis project. Nat Genet 45: 1113-1120, 2013.

15. Ha M, Han ME, Kim JY, Jeong DC, Oh SO and Kim YH: Prognostic role of TPD52 in acute myeloid leukemia: A retrospective multicohort analysis. J Cell Biochem 120: 3672-3678, 2019.

16. Han ME, Kim JY, Kim GH, Park SY, Kim YH and Oh SO: SAC3D1: A novel prognostic marker in hepatocellular carcinoma. Sci Rep 8: 15608, 2018.

17. Rhodes DR, Yu J, Shanker K, Deshpande N, Varambally R, Ghosh D, Barrette T, Pandey A and Chinnaiyan AM: ONCOMINE: A cancer microarray database and integrated data-mining platform. Neoplasia 6: 1-6. 2004.

18. Cho SH, Pak K, Jeong DC, Han ME, Oh SO and Kim YH: The AP2M1 gene expression is a promising biomarker for predicting survival of patients with hepatocellular carcinoma. J Cell Biochem 120: 4140-4146, 2019.

19. Kim YH, Jeong DC, Pak K, Goh TS, Lee CS, Han ME, Kim JY, Liangwen L, Kim CD, Jang JY, et al: Gene network inherent in genomic big data improves the accuracy of prognostic prediction for cancer patients. Oncotarget 8: 77515-77526, 2017.

20. Uno H, Cai T, Pencina MJ, D'Agostino RB and Wei LJ: On the C-statistics for evaluating overall adequacy of risk prediction procedures with censored survival data. Stat Med 30: 1105-1117, 2011.

21. Hoshida Y, Nijman SM, Kobayashi M, Chan JA, Brunet JP, Chiang DY, Villanueva A, Newell P, Ikeda K, Hashimoto M, et al: Integrative transcriptome analysis reveals common molecular subclasses of human hepatocellular carcinoma. Cancer Res 69: 7385-7392, 2009.

22. Shtraizent N, DeRossi C, Nayar S, Sachidanandam R, Katz LS, Prince A, Koh AP, Vincek A, Hadas Y, Hoshida Y, et al: MPI depletion enhances O-GlcNAcylation of p53 and suppresses the Warburg effect. Elife 6: pii: e22477, 2017.

23. Subramanian $P$ and Haas NB: Recent advances in localized RCC: A focus on VEGF and immuno-oncology therapies. Urol Oncol 36: 23-30, 2018.

24. Wang Y, Chen L, Wang G, Cheng S, Qian K, Liu X, Wu CL, $\mathrm{Xiao} Y$ and Wang X: Fifteen hub genes associated with progression and prognosis of clear cell renal cell carcinoma identified by coexpression analysis. J Cell Physiol 234: 10225-10237, 2019.

25. Guan L, Tan J, Li H and Jin X: Biomarker identification in clear cell renal cell carcinoma based on miRNA-seq and digital gene expression-seq data. Gene 647: 205-212, 2018.

26. Gao C, Zhou C, Zhuang J, Liu L, Liu C, Li H, Liu G, Wei J and Sun C: MicroRNA expression in cervical cancer: Novel diagnostic and prognostic biomarkers. J Cell Biochem 119 7080-7090, 2018.
27. Joseph J, Niggemann B, Zaenker KS and Entschladen F: The neurotransmitter gamma-aminobutyric acid is an inhibitory regulator for the migration of SW 480 colon carcinoma cells. Cancer Res 62: 6467-6469, 2002.

28. Azuma H, Inamoto $T$, Sakamoto $T$, Kiyama S, Ubai $T$, Shinohara Y, Maemura K, Tsuji M, Segawa N, Masuda H, et al: Gamma-aminobutyric acid as a promoting factor of cancer metastasis; induction of matrix metalloproteinase production is potentially its underlying mechanism. Cancer Res 63: 8090-8096, 2003.

29. Plummer PN, Colson NJ, Lewohl JM, MacKay RK, Fernandez F, Haupt LM and Griffiths LR: Significant differences in gene expression of GABA receptors in peripheral blood leukocytes of migraineurs. Gene 490: 32-36, 2011

30. Paik S, Shak S, Tang G, Kim C, Baker J, Cronin M, Baehner FL, Walker MG, Watson D, Park T, et al: A multigene assay to predict recurrence of tamoxifen-treated, node-negative breast cancer. $\mathrm{N}$ Engl J Med 351: 2817-2826, 2004.

31. Wittner BS, Sgroi DC, Ryan PD, Bruinsma TJ, Glas AM, Male A, Dahiya S, Habin K, Bernards R, Haber DA, et al: Analysis of the MammaPrint breast cancer assay in a predominantly postmenopausal cohort. Clin Cancer Res 14: 2988-2993, 2008.

32. Chen HY, Yu SL, Chen CH, Chang GC, Chen CY, Yuan A, Cheng CL, Wang CH, Terng HJ, Kao SF, et al: A five-gene signature and clinical outcome in non-small-cell lung cancer. N Engl J Med 356: 11-20, 2007.

33. Goh TS, Lee JS, II Kim J, Park YG, Pak K, Jeong DC, Oh SO and Kim YH: Prognostic scoring system for osteosarcoma using network-regularized high-dimensional Cox-regression analysis and potential therapeutic targets. J Cell Physiol 234: 13851-13857, 2019.

34. Pak K, Kim YH, Suh S, Goh TS, Jeong DC, Kim SJ, Kim IJ, Han ME and Oh SO: Development of a risk scoring system for patients with papillary thyroid cancer. J Cell Mol Med 23: 3010-3015, 2019.

35. Kim YH, Jeong DC, Pak K, Han ME, Kim JY, Liangwen L, Kim HJ, Kim TW, Kim TH, Hyun DW and Oh SO: SLC2A2 (GLUT2) as a novel prognostic factor for hepatocellular carcinoma. Oncotarget 8: 68381-68392, 2017.

36. Nault JC, De Reynies A, Villanueva A, Calderaro J, Rebouissou S, Couchy G, Decaens T, Franco D, Imbeaud S, Rousseau F, et al: A hepatocellular carcinoma 5-gene score associated with survival of patients after liver resection. Gastroenterology 145: 176-187, 2013.

37. van 't Veer LJ, Dai H, van de Vijver MJ, He YD, Hart AA, Mao M, Peterse HL, van der Kooy K, Marton MJ, Witteveen AT, et al: Gene expression profiling predicts clinical outcome of breast cancer. Nature 415: 530-536, 2002.

This work is licensed under a Creative Commons Attribution-NonCommercial-NoDerivatives 4.0 International (CC BY-NC-ND 4.0) License. 